\title{
ATENDIMENTO PRIORITÁRIO DO ESTATUTO DA PESSOA COM DEFICIÊNCIA E O PRINCÍPIO DA PRIORIDADE DO REGISTRO DE IMÓVEIS
}

\section{ARTIGO ORIGINAL}

NETO, Alexandre Moura Lima1', AGUAIR, Alessandra Anchieta Moreira Lima de², NETO, Haroldo Corrêa Cavalcanti ${ }^{3}$

NETO, Alexandre Moura Lima. AGUAIR, Alessandra Anchieta Moreira Lima de. NETO, Haroldo Corrêa Cavalcanti. Atendimento prioritário do estatuto da pessoa com deficiência e o princípio da prioridade do registro de imóveis. Revista Científica Multidisciplinar Núcleo do Conhecimento. Ano 06, Ed. 09, Vol. 03, pp. 4563. Setembro de 2021. ISSN: 2448-0959, Link de acesso: https://www.nucleodoconhecimento.com.br/lei/atendimento-prioritario, $\quad$ DOI: 10.32749/nucleodoconhecimento.com.br/lei/atendimento-prioritario

\section{RESUMO}

O presente estudo tem como objetivo analisar 0 aparente conflito entre 0 atendimento prioritário do estatuto da pessoa com deficiência e o princípio da prioridade do registro de imóveis, ou seja, se essa garantia legal, confere à pessoa portadora de deficiência prioridade quando da anotação de direitos em Cartórios. No que diz respeito à metodologia utilizada destaca-se que quanto aos fins este estudo de classifica como descritiva e explicativa e, quanto aos meios, se classifica como bibliográfica, recorrendo ao uso de materiais como livros, artigos, revistas e reportagens sobre o tema. A pesquisa se caracteriza, ainda, como de abordagem qualitativa. Pretendeu-se demonstrar que a pessoa com deficiência tem direito assegurado nos termos da Lei 13.143/2015 de ser atendida de forma rápida, eficaz e

\footnotetext{
${ }^{1}$ Mestre em Cultura e Sociedade pela Universidade Federal do Maranhão (UFMA). ORCID: https://orcid.org/0000-0002-7232-8449

2 É Mestre em Meio Ambiente pelo Programa de Pós-Graduação em Meio Ambiente da Universidade Ceuma. ORCID: https://orcid.org/0000-0003-4017-1579

${ }^{3}$ Especialização em Direito Imobiliário. ORCID: https://orcid.org/0000-0003-1746-1965
} 
individualizada, inclusive em Cartórios de Registros de Imóveis, todavia não goza de privilégios em face da prioridade registral tendo em vista o princípio da prioridade registral. A partir de decisões tomadas pelas varas registrais de São Paulo, como resultado, tem-se que a disposição específica da Lei n. 6.015/1973 prevalece em relação ao direito de atendimento prioritário de determinados públicos, Lei 13.143/2015, visto que trata de um direito material de prioridade, sendo entendido que conceder atendimento prioritário fora dos requisitos do art. 186 da Lei $n$. 6.015/1973, representaria inegável afronta aos ditames legais, o que comprometeria o atendimento ao direito à igualdade, premissa também do Estatuto da Pessoa com Deficiência.

Palavras-Chave: Estatuto da Pessoa com Deficiência, Registro de Imóveis, Princípio da Prioridade.

\section{INTRODUÇÃO}

O dia a dia de pessoas com necessidades especiais é complexo, considerando as suas limitações e a falta de preparo da sociedade para recebê-las, tanto em relação à infraestrutura quanto na mentalidade dos indivíduos, assim, elas acabam sendo excluídas socialmente, atividades como se divertir, estudar e ir ao trabalho, que são tarefas simples e rotineiras se tornam um desafio a ser enfrentado.

Como bem destaca Carlos Henrique Ribeiro da Silva (2008), a falta de tolerância entre os diferentes, no decorrer da história, fez com que as minorias fossem sempre tratadas de forma relativamente agressiva e confusa, rotulando, segregando, discriminando e excluindo os que se afastavam do padrão, este que é formado a partir de um modelo hegemônico. Outro fator bastante comum, originado pela falta do entendimento acerca das diferenças entre as pessoas está na própria pessoa considerada diferente, que assume atitudes muito particulares como autopunição, isolamento e a agressividade. Assim, acredita-se que a falta de tolerância com os diferentes possui raízes históricas, apesar de muito já se ter avançado em relação ao assunto. 
Durante muito tempo no Brasil a pessoa com deficiência foi considerada incapaz, com as mudanças sociais esse fato foi sendo modificado e essas pessoas passaram a ser reconhecidas como sujeitos de direito e capazes de tomar suas decisões, tanto que no ano de 2015, a Lei n. 13.146 alterou o Código Civil, instituindo o Estatuto da Pessoa com Deficiência. De acordo com Lago (2016), a publicação do referido Estatuto visou a superação do assistencialismo e a superação de barreiras das pessoas com deficiência, como premissa para assegurar o direito à dignidade, civilidade e plena participação na sociedade. Todavia, de acordo com o autor, a prioridade dada a essas pessoas pelo Estatuto entra em conflito com o princípio da prioridade no registro de imóveis nos termos da Lei 6.015/1973 e pelo Código Civil por ordem de apresentação dos títulos, sendo este o foco do presente estudo. Assim, buscará se discutir no presente ensaio acerca da prioridade no Estatuto da Pessoa com Deficiência versus a prioridade descrita na Lei de Registros Públicos (Lei 6.015/73). Tendo como questão norteadora: se a pessoa portadora de deficiência, em face do que dispõe o Estatuto da Pessoa com Deficiência, goza de privilégios em face dos demais, na consagração da prioridade registral?

O princípio da prioridade, no direito imobiliário, consiste no fato de que terá sempre prioridade para a realização dos procedimentos de registro o título apresentado em primeiro lugar perante o cartório de imóveis. De acordo com o art. 186 da Lei de Registros Públicos (Lei 6.015/73), "o número de ordem determinará a prioridade do título, e esta a preferência dos direitos reais, ainda que apresentados pela mesma pessoa mais de um título simultaneamente", de modo que a prioridade será determinada para aquele que primeiro protocolar o título no cartório de imóveis. E no protocolo do cartório, "todos os títulos tomarão o número de ordem que lhes competir em razão da sequência rigorosa de sua apresentação" (art. 182).

Destaca-se ao longo dos últimos séculos o sistema registral brasileiro vem sendo constantemente modificado por meio de legislações que vislumbram acompanhar a evolução da sociedade como um todo, permitindo às transações imobiliárias a segurança, publicidade e eficácia tanto para os que desta participam, quanto para os que por ela se interessarem. De acordo com Lima (2011) tanto a atividade notarial 
como a de registros atuam como meio de pacificação social, assegurando a publicidade, autenticidade, segurança e eficácia dos atos jurídicos de modo preventivo.

Importante destacar que apesar das atividades notariais e registrais estarem associadas elas não devem ser confundidas. Benício (2005) elucida que essa diferença pode ser vista quando se fala na função do registrador e tabelião (notário), onde o primeiro atua com o objetivo de legitimar e dar publicidade aos atos, enquanto o segundo engloba a assessoria em suas funções com posterior legitimação, autenticidade e formalização dos atos jurídicos. Ainda diferenciando as duas atividades, o autor afirma que o notário tem como função predominante a segurança dinâmica ${ }^{[4]}$, já o registrador a segurança estática[5], enfim, enquanto o notário busca acautelar o actum (ato), o registrador se limita a publicar o dictum (dito).

As atividades realizadas no âmbito do Direito Notarial e de Registros devem ser vistas em sua relevância social, conforme salienta Ceneviva (2008) sua importância deve-se a abrangência dos atos, que envolve desde o nascimento até o óbito, registrando e dando publicidade a todos os atos legais realizados pelos cidadãos durante suas vidas, como casamento, divórcio, partilhas, inventários, contratos de compra e venda, entre outros, regularizando todas as ações realizadas. Assim, tratase de atividades diretamente relacionadas ao cotidiano dos indivíduos.

Destaca-se a relevância social deste estudo, considerando que envolve uma minoria da população que precisa de atenção no atendimento de seus direitos, podendo melhor esclarecer sobre os possíveis conflitos com o princípio da prioridade no registro de imóveis, bem como a relevância profissional e acadêmica, já que muitas ainda são as controvérsias que giram em torno do tema, restando, sendo escassos os estudos realizados e publicados sobre o problema em questão, portanto, esta pesquisa resta justificada.

No que diz respeito à metodologia utilizada destaca-se, com base em Maria Cecilia de Souza Minayo (2007), que quanto aos fins este estudo de classifica como 
descritiva e explicativa e, quanto aos meios, se classifica como bibliográfica, recorrendo ao uso de materiais acessíveis ao público como livros, artigos, revistas e reportagens sobre o tema. A pesquisa se caracteriza, ainda, como pura de abordagem qualitativa. Foi tomado como base o que outros autores escreveram, podendo-se compreender diferentes pontos de vistas sobre o assunto, direcionando o estudo no melhor caminho para tornar a pesquisa confiável.

Nesse contexto, como dito anteriormente, o presente estudo tem como objetivo analisar o conflito entre 0 atendimento prioritário do estatuto da pessoa com deficiência e o princípio da prioridade do registro de imóveis.

\section{AS PESSOAS COM DEFICIÊNCIA EM UM CONTEXTO HISTÓRICO}

Desde o início dos tempos há registros de pessoas com necessidades especiais. A ideia cultural de invalidez, impotência e dependência, das pessoas com dificuldades motoras atravessam culturas, sociedades, grupos socioculturais, religiões e práticas sociais. A quebra da expectativa dos pais com o nascimento de filhos acometidos por algum tipo de problema motor, a aquisição de alguma sequela advinda de doenças ou acidentes, certamente são eventos de difícil enfrentamento e já foram vivenciados em muitas culturas de formas atípicas (GUGEL, 2011).

De acordo com Débora Fazolin Koyama (2017) as pessoas com deficiência física sempre enfrentaram diversas situações questões de exclusão e segregação perante a sociedade, no período da Grécia antiga isso era especialmente retratado pela cidade-estado de Esparta, visto que crianças que nasciam com algum tipo de deficiência eram consideradas como inúteis àquela sociedade e atiradas a um abismo.

Débora Fazolin Koyama (2017) diz que ao longo da história as pessoas com deficiência sempre travaram uma grande luta pela vida e para conquistar seu espaço na sociedade, já que a cultura imposta pela sociedade as pessoas sempre as marginalizou e agiu de maneira excludente com essas pessoas. 
As pessoas com deficiência passaram a ter alguns de seus direitos reconhecidos apenas na Declaração Universal de Direitos Humanos e a partir de então foi dado um pontapé no que viria a ser a normatização de princípios fundamentais a essas pessoas, desse momento surgiram: o princípio da dignidade da pessoa humana, princípio da igualdade, dentre outras normas protetivas. (KOYAMA, 2017)

O Egito Antigo, de acordo com Clemente (2015, p. 34) era conhecido como a "Terra dos Cegos porque seu povo era constantemente acometido de infecções nos olhos, que resultavam em cegueira". Por outro lado, há registros históricos que em locais da Grécia antiga e Esparta, crianças com deformidades eram abandonadas nas florestas ou atiradas de desfiladeiros.

As leis romanas da Antiguidade não protegiam as pessoas com deficiência, ao contrário, legitimavam os pais a matarem suas crianças, através da prática do afogamento, abandonados em cestos no Rio Tibre, ou em outros lugares sagrados, sendo alguns expostos e usados como entretenimento nos circos. Estudos realizados por Lourenzetto (2006) confirmam como nos quatro primeiros séculos da era cristã, não havia nenhuma expressão significativa que favorecesse a inserção das pessoas com deficiências como sujeitos de dignidade e direitos.

$\mathrm{Na}$ antiguidade, há poucos registros da relação da sociedade com os deficientes no cotidiano. Através de passagens bíblicas pode ser percebida a discriminação existente na época contra pessoas portadoras de deficiência, pois são sempre mencionados como pedintes ou rejeitados pela comunidade, ou seja, viviam à margem da convivência social e comunitária. Muitos acreditavam que essas pessoas eram castigadas pelos deuses (Lourenzetto, 2006, p. 3).

$\mathrm{Na}$ Idade Média, a deficiência foi considerada um fenômeno metafísico, determinado pela possessão demoníaca ou como castigo de Deus. Tais pessoas eram vistas como "possuidoras de um mal devido ao pacto com o demônio", justificativa usada para legitimar socialmente o uso extremo da fogueira como castigo (MAINIERI; ROSA, 2012).

Acreditava-se que tal prática, possibilitava a humilhação e a vitória contra o suposto inimigo que era preciso derrotar. Para Maria Aparecida Gugel (2011) além de atribuir 
às pessoas com deficiências poderes especiais de feiticeiros, as crianças que sobreviviam eram separadas de suas famílias e quase sempre ridicularizadas.

Marcella Lourenzetto (2006) faz referências sobre documentos papais, que no caso de uma pessoa com deficiência mental fugir de sua razão, ele era considerado um ser diabólico, passando a ser perseguido, torturado e exterminado. No século XV, tais indivíduos ainda não eram percebidos como pessoas humanas.

Nesses exemplos, fica explícito como a segregação e o fatalismo atingiam as pessoas com problemas de cegueira e quaisquer outros que fugiam dos padrões estabelecidos como normais (BIANCHETTI; FREIRE, 2007). A pena de amputação também foi usada como controle e punição dos traidores nas Constituições romanas do Imperador Leão III, processo que vigorou no Império Romano e no Oriente.

O raciocínio introduzido notadamente no período da Inquisição adotava a prática da queima de pessoas que trouxessem em seu corpo alguma diferença considerada não-normal, ou que apresentasse ideias divergentes do status quo ou que se comportasse de maneira considerada não-adequada. Por esta razão, nos autos da Inquisição e nas justificativas da Igreja não se encontram afirmações de que ela tenha queimado pessoas. Como afirma Lucídio Bianchetti e Ida Maria Freire (2007, p. 33), a Igreja enunciava tal ação como "[...] purificação pelas chamas". Outra explicação sobre a existência de cegos, mudos, paralíticos, loucos e leprosos era a de que estes eram concebidos como:

[...] instrumentos de Deus para alertar aos homens e as mulheres sobre comportamentos adequados ou para the proporcionar a oportunidade de fazer caridade. Assim, a desgraça de uns proporcionava meios de salvação a outros. (BIANCHETTI; FREIRE, 2007, p. 33).

Segundo Maria Aparecida Gugel (2011), o processo das pessoas com deficiência passarem a serem reconhecidas como pessoas de dignidade e valor surgiu com os primeiros hospitais de caridade. Para a autora, entre 1214 e 1270, o rei Luís IX fundou o primeiro hospital para pessoas cegas vítimas das Cruzadas. A construção de novas concepções sobre a deficiência só foi historicamente possível no século 
$\mathrm{XVI}$, quando o avanço tecnológico e científico possibilitou o aparecimento de concepções distintas na Medicina.

Foi apenas no século XVI, com o avanço científico no campo da medicina, que apareceram as primeiras falas dissonantes a respeito do tratamento dispensado aos deficientes (GUGEL, 2011).

Grande parte dos homens e das mulheres limitava-se a viver seu dia a dia, de forma miserável, envolvidos com a produção para a subsistência. Com o gradativo predomínio da produção voltada para o mercado, a possibilidade de acumulação, o desenvolvimento de uma ciência e novas tecnologias, obtém um relativo domínio sobre a natureza. Com esse processo, criaram-se as condições materiais, sociais e culturais para a construção de processos emancipatórios que possibilitem a passagem da esfera da necessidade para liberdade.

Só a partir do século $\mathrm{XVI}$, é que foi possível outro processo histórico diferente da situação histórica anterior. Com os avanços da medicina ocorridos no século XVII, passou-se a compreender a deficiência física como um objeto de estudo da prática médica. O processo de medicalização das deficiências implicou na crítica às visões presentes historicamente, de que em cada homem presidia um estado mórbido, a presença de demônios maus influenciando a saúde e a doença (BIANCHETTI; FREIRE, 2007).

As explicações metafísicas da esfera religiosa são confrontadas com o paradigma científico positivista, de modo que a visão teológica sobre a diferença perde força, mas influencia as bases teóricas para uma interpretação organicista. Nos idos do Século XVII, desencadeia-se uma grande clausura de todos que não participam da Universal Razão, que estava surgindo. Aquele que mostrava ausência de razão em qualquer de suas formas, como razão lógica, política, moral era enclausurado (BIANCHETTI; FREIRE, 2007).

Somente a partir de meados do século XIX é que começam a surgir as primeiras instituições para cuidados com as pessoas com deficiências físicas. Por muito tempo 
tais pessoas foram consideradas apenas como pacientes que necessitavam de cuidados especiais e estes eram vistas como pessoas com baixo potencial e com inúmeras limitações. No Brasil, nesse mesmo período, foram instituídos por ordem de D. Pedro II, o Imperial Instituto dos Meninos Cegos e o Imperial Instituto de Surdos-Mudos, fato este considerado como uma das primeiras atitudes brasileiras para integração dos deficientes na sociedade (SOUSA, 2012).

Entretanto, a criação de dispositivos de enclausuramento gerou também processos de segregação do meio social, resultando com isso, a construção do que Erving Goffman (2008, p.13) define como estigma, "[...] um tipo especial de relação entre atributo e estereótipo", sendo compreendido no contexto das relações humanas e não substantivado. "Um atributo que estigmatiza alguém pode confirmar a normalidade de outrem".

A questão da deficiência obtém outro enfoque em função da observação da mudança de paradigmas, notadamente nos anos 70 , do século passado, propugnam-se ações integrativas, no sentido de favorecer a presença/inserção das pessoas com deficiência nos mesmos âmbitos sociais que as demais. Porém esta possibilidade aparece como algo utópico em sua funcionalidade real, pois como explica Erving Goffman (2008, p. 134):

A situação especial do estigmatizado é que a sociedade lhe diz que ele é um membro do grupo mais amplo, o que significa que ele é um ser humano normal, mas também que ele é até certo ponto, "diferente", e que seria absurdo negar essa diferença. A diferença, em si, deriva da sociedade, porque em geral, antes que uma diferença seja importante ela deve ser coletivamente conceitualizada pela sociedade como um todo.

Desse modo, a inserção deste público nas diferentes esferas sociais é crescente a cada ano, embora as instalações físicas, a oferta de material e a capacitação de profissionais para o atendimento das pessoas com necessidades especiais ainda sejam precários, focando-se este estudo nos direitos destes cidadãos, mais especificamente integração, inclusão e igualdade, a partir do princípio basilar da dignidade da pessoa humana. 


\section{DIREITOS HUMANOS COM ÊNFASE NA PESSOA COM DEFICIÊNCIA}

Os direitos humanos com ênfase na pessoa com deficiência, além da dignidade da pessoa humana e da igualdade, precisam trazer em destaque 0 direito à mobilidade e à cidade, bem como à educação e à saúde, tendo em vista que são fatores cruciais para que se possa garantir a inclusão social dessas pessoas. Durante todo o processo evolutivo da civilização humana houve a busca por direitos que vão desde a locomoção até a circulação em ambientes públicos e privados de forma independentes.

Historicamente, as pessoas foram desrespeitadas e excluídas totalmente do convívio social, principalmente do contexto social e isso se deu baseado nas ideias que se tinham sobre o ser humano e a sociedade que foi inculcada nos indivíduos formando um modelo mental que se instala neste e não mais desaparece. Apenas se transforma (LOPES et al., 2009, p. 29).

A perspectiva de direitos do cidadão conquistada historicamente trouxe a ideia da integração, de inclusão, de igualdade como forma de enfrentamento dos processos de exclusão social, discriminação e estigmatização. Este processo é fundamental, à exemplo de calçadas que garantam o direito de ir e vir de qualquer cidadão na cidade onde vive.

No Brasil, esse processo implicou no reconhecimento do direito à acessibilidade. $\mathrm{Na}$ Constituição Federal, o cap. VII, art. 227 prevê a "facilitação do acesso aos bens e serviços coletivos, com a eliminação de preconceitos e obstáculos arquitetônicos", dispondo, portanto, de normas que garantia a construção de adaptação de logradouros, de edifícios públicos e de transporte coletivo. (NOGUEIRA, 2010, p. 51). Em 1981, por exemplo, a Organização Das Nações Unidas - ONU reconheceu em uma convenção o ano internacional de pessoas com deficiência. Em 1989, estes direitos foram alterados pela Lei $\mathrm{n}^{\circ}$. 7.853 , cujo objeto visa instituir "a tutela jurisdicional de interesses coletivos ou difusos dessas pessoas, disciplina a atuação do Ministério Público, define crimes, e dá outras providências" (BRASIL, 1989). A mesma lei determina o cumprimento da execução das normas pelos municípios de 
forma a promover a funcionalidade de edificações e vias públicas ao portador de deficiência.

Por último, foi criada a Lei Federal № 10.098 de 19 de dezembro de 2000[6], posteriormente regulamentada pelo decreto no. 5.296 de 02 de dezembro de 2004[7], normatizando a questão da acessibilidade como meta de adaptação e instituição de acesso. Até hoje, entretanto, esta lei não foi posta em prática, já que itens como, acesso a edifícios públicos, permanência e utilização disponibilizadas nesses prédios, como educação e saúde não foram totalmente contemplados. As calçadas são o retrato da sociedade excludente, tornando necessário resolver questões emergenciais, como buracos nas ruas, carros nas calçadas interrompendo a mobilidade, padronização de rampas, corrimão, passarelas, banheiros públicos e sinalização especial para que possam ser minimizados os problemas de acessibilidade (COELHO, 2010).

Neste sentido, o direito à acessibilidade é um fator indispensável não somente para aqueles que possuem algum tipo de deficiência ou mobilidade reduzida e sim para a sociedade como um todo, pois se baseando no princípio da igualdade todos são iguais perante a lei e gozam dos mesmos direitos de ir e vir, de educação, lazer, trabalho, habitação, turismo e cultura. Conforme a Declaração dos Direitos das Pessoas Deficientes, aprovada em assembleia geral da Organização das Nações Unidas (ONU), no ano de 1975, proclama dentre outras resoluções que: "As pessoas deficientes têm direito a medidas que visem capacitá-las a tornarem-se tão autoconfiantes quanto possível".

A Carta Mundial do Direito à Cidade aprovada no Fórum Social das Américas em Quito, o Fórum Mundial Urbano de Barcelona em 2004 e o V Fórum Social Mundial de Porto Alegre em 2005 estabelece compromissos entre governos e sociedade civil organizada com vistas a promover cidades pautadas nos princípios da solidariedade, liberdade, igualdade, justiça social e dignidade.

O direito à cidade é definido na Carta, como: "O usufruto equitativo das cidades dentro dos princípios de sustentabilidade, democracia e justiça social [...] é 
interdependente a todos os direitos internacionalmente reconhecidos". A cidade é neste documento concebida como "espaço coletivo culturalmente rico e diversificado que pertence a todos os cidadãos" (CARTA MUNDIAL DO DIREITO À CIDADE, 2004, p. 2). No que trata da proteção especial de grupos e pessoas vulneráveis, a Carta da Cidade afirma:

As cidades mediante políticas de afirmação positiva aos grupos vulneráveis devem suprir os obstáculos de ordem política, econômica e social que limitam a liberdade, equidade e de igualdade dos cidadãos(ãs), e que impedem o pleno desenvolvimento da pessoa humana e a participação efetiva na organização política, econômica, cultural e social da cidade (CARTA MUNDIAL DO DIREITO À CIDADE, 2004, p. 3).

Em relação à mobilidade urbana, afirma o artigo 13:

1. As cidades garantem o direito a mobilidade e circulação na cidade através de um sistema e transporte públicos acessíveis a todas as pessoas segundo um plano de deslocamento urbano e interurbano e, em base nos meios de transportes adequados as diferentes necessidades sociais (de gênero, idade, incapacidade) e ambientais, com preços adequados a renda dos cidadãos(ãs). Será estimulado o uso de veículos não contaminantes e reservando áreas aos pedestres de maneira permanente a certos momentos do dia.

2. As cidades promoverão a remoção de barreiras arquitetônicas para a implantação dos equipamentos necessários ao sistema de mobilidade e circulação e a adaptação de todas as edificações públicas ou de uso público, dos locais de trabalho, para garantir a acessibilidade das pessoas portadoras de necessidades especiais (CARTA MUNDIAL DO DIREITO À CIDADE, 2004, p. 3).

Vale aqui ressaltar que quando se fala em acessibilidade não se resume ao espaço físico onde se está instalado, trata-se da cidade como um todo que representa o processo político, social, econômico e intelectual da sociedade. 
No âmbito da educação e da saúde, ressalta-se que a inclusão escolar se configura como um direito do cidadão garantindo de forma universal, destacando-se como marco desse processo a Declaração de Salamanca que faz ênfase à educação inclusiva, seguindo as convenções e direitos humanos, voltados para as crianças e adolescentes, apresentando aqui, as principais, como mérito de conhecimento base do assunto. O documento teve este nome por se tratar de uma Conferência Mundial sobre Educação Especial em Salamanca, em 1994, esta tinha como objetivo reestruturar a reforma de políticas de acordo com a inclusão, afirmando que:

Toda criança tem direito fundamental à educação, e deve ser dada a oportunidade de atingir e manter o nível adequado de aprendizagem, toda criança possui características, interesses, habilidades e necessidades de aprendizagem que são únicas, sistemas educacionais deveriam ser designados e programas educacionais deveriam ser implementados no sentido de se levar em conta a vasta diversidade de tais características e necessidades, aqueles com necessidades educacionais especiais devem ter acesso à escola regular, que deveria acomodá-los dentro de uma Pedagogia centrada na criança, capaz de satisfazer a tais necessidades, escolas regulares que possuam tal orientação inclusiva constituem os meios mais eficazes de combater atitudes discriminatórias criando-se comunidades acolhedoras, construindo uma sociedade inclusiva e alcançando educação para todos; além disso, tais escolas provêm uma educação efetiva à maioria das crianças e aprimoram a eficiência e, em última instância, o custo da eficácia de todo o sistema educacional (...)" Assim cita o documento (ONU, 2010, p. 78).

Esta proclamação nos coloca na obrigatoriedade de oferecer e oportunizar as crianças e adolescentes programas específicos e avaliação adaptada, garantindo o desenvolvimento pleno e o desenvolvimento das potencialidades de cada indivíduo. Para isso, as readaptações de Currículo deveriam ser pensadas e nele estar contemplando a garantia de direito.

Trata-se de um acordo internacional sobre os direitos da criança e do adolescente. Considerando que, de acordo com os princípios proclamados na Carta das Nações Unidas, o reconhecimento da dignidade inerente e dos direitos iguais e inalienáveis de todos os membros da família humana é o fundamento da liberdade, da justiça e da paz no mundo e tendo em mente que os povos das Nações Unidas reafirmaram na sua Carta a sua confiança nos direitos humanos fundamentais e na dignidade e 
valor da pessoa humana e têm determinado a promover o progresso social e melhores padrões de vida em maior liberdade.

A Política Nacional de Educação Especial (PNEE) na Perspectiva da Educação Inclusiva (PEI) (2008) evidencia a necessidade de confrontar a segregação de alunos no ambiente escolar e propõe uma educação especial que se desenvolva de forma complementar, reafirmando o sistema único de ensino.

Nesse contexto, os direitos humanos são universais não podendo por qualquer motivo serem excluídos qualquer cidadão por suas condições físicas, mentais, ou por cor, raça, costume ou classe social, portanto, cabe às autoridades a elaboração de políticas públicas para atendimento desses indivíduos de forma igualitária.

Assim, reconhecer que as pessoas com deficiência têm prioridades, dentre elas, de um atendimento preferencial, rápido e individualizado concretizam o gozo dos direitos fundamentais estampados na Constituição Federal de 1988. Contudo, há que se esclarecer, que por tratar-se de um direito personalíssimo, esse direito deverá ser exercitado em proveito próprio da pessoa com deficiência, ou por pessoas que se achem na condição de vulnerabilidade, nos termos da Lei Federal 10.048, de 8 de novembro de 2000[8], que consagrou a prioridade de atendimento às pessoas que especifica: pessoas portadoras de deficiência, gestantes, lactantes, pessoas acompanhadas por crianças de colo, além dos idosos.

Evidencie-se, ainda, que a condição pessoal da parte não é o destaque principal do Estatuto da Pessoa com Deficiência, o que se busca é o atendimento preferencial, imediato e individualizado da parte vulnerável, no nosso estudo, a pessoa com deficiência em Cartórios.

\section{ESTATUTO DA PESSOA COM DEFICIÊNCIA E O PRINCÍPIO DA PRIORIDADE DO REGISTRO DE IMÓVEIS}

No âmbito dos serviços notariais e registrais, além da observância dos princípios basilares da Administração Pública, se faz necessário que os tabeliões e 
registradores também atendam a princípios considerados como específicos dessas atividades. Importante entender que os princípios são maleáveis, tendo em vista que eles se adaptam às circunstâncias históricas e sociais pelas quais passam.

Os princípios aplicados aos serviços registrais envolvem as ações a serem realizadas durante todo o processo de registro, desde a inscrição até a rogação, estando relacionados ao Direito Imobiliário. O princípio da inscrição, de acordo com Carvalho (2011), é o início do processo, sendo responsável pela constituição, transmissão, modificação ou extinção dos direitos reais. Trata-se, desse modo, do registro dos atos que alteram ou extinguem qualquer ato do registro.

Ainda se considera o princípio da publicidade já mencionado como princípio basilar da Administração Pública, devendo os registradores tornarem públicos os registros realizados no âmbito de seus Cartórios. De acordo com Ceneviva (2008), a publicidade como princípio da atividade registral visa o cumprimento de seu tríplice função que é a de transmitir o registro ao conhecimento de terceiros, informar sobre bens e direitos de indivíduos que recebam benefícios advindos do ato de registro, sacrificando, mesmo que parcialmente, seu direito à privacidade e à intimidade e promover os atos para fins estatísticos, tendo em vista o interesse nacional ou a fiscalização pública.

O princípio da presunção da verdade aplicado aos serviços registrais também é decorrente da fé pública que Ihes é concedida juntamente com a delegação da função. Vasconcelos e Cruz (2000) elucidam que a fé pública deve se estender a todos os atos realizados no âmbito dos serviços registrais, respondendo de forma positiva à existência dos direitos reais. Assim, sempre se presume que tudo que estiver inscrito no registro de imóveis é verdade até que se prove o contrário.

Por sua vez, o princípio da prioridade trata da questão de ordem das inscrições no registro de imóveis, devendo o registrador considerar a ordem cronológica de apresentação dos títulos, conforme art. 186 da Lei n. 6.015/1973. Antunes (2005) ressalta que é a ordem cronológica que deve determinar a prioridade do título e a preferência do direito real. 
O princípio da especialidade ou determinação dos registros traz que a inscrição deve ser feita de forma que a descrição do imóvel seja precisa e com suas características peculiares, como a matrícula, número de ordem, data, identificação do imóvel, confrontações, localização e área. Além disso, é necessário constar também dados do seu proprietário como nome, domicílio, nacionalidade, estado civil, profissão, número do Registro Geral (RG) e, em caso de pessoa jurídica, deve constar cede social e o número do Cadastro Nacional de Pessoa Jurídica (CNPJ). A correta descrição desses dados é fundamental para conferir segurança jurídica aos atos realizados (ANTUNES, 2005).

Dando continuidade à descrição dos princípios dos serviços registrais tem-se o princípio da qualificação, da legalidade ou da legitimidade que, de acordo com Antunes (2005), o registrador deve examinar o título apresentado considerando a forma, a validade e conformidade com a lei. Galiani (1995) menciona, ainda, que até mesmo para examinar o título que the é entregue, o registrador deve se valer da legislação, não podendo ir além dos limites estabelecidos por lei, devendo analisar somente os aspectos formais dele.

O princípio da continuidade também faz parte do rol de princípios aplicados aos serviços registrais, sendo destacado por Antunes (2005) como um dos alicerces desses serviços. Sobre a aplicação desse princípio, Balbino Filho (2001) elucida que ele traz a obrigatoriedade de continuidade do registro, mantendo a conexão entre os diferentes negócios que vieram a modificar a situação jurídico-real. Desse modo, todas as alterações que ocorrerem no título devem ser registradas no mesmo documento, preservando-se as informações anteriores.

Por fim, tem-se o princípio da instância ou rogação, que trata da ação feita pelo registrador a partir de requerimento das partes. De acordo com Balbino Filho (2001), o princípio da instância ou rogação diz respeito à solicitação de qualquer ato registral, devendo ser simples, independente de forma especial, podendo ser expressa ou tácita. Expressa quando for manifestada de forma clara pelas partes e tácita quando o registrador consegue identificar a vontade das partes contando com sua experiência. 
Diante do exposto, os serviços registrais devem ser realizados com observância aos princípios citados, não se podendo esquecer que os princípios basilares da Administração Pública devem ser considerados em todas as atividades realizadas pelos registradores no âmbito de suas funções.

As discussões em torno do princípio da prioridade do registro de imóveis tem sido motivo de discussão, tanto que é possível identificar casos julgados que consideram os conflitos com direitos de determinados públicos. Lago (2016) cita a concessão de prioridade no atendimento de advogados e a concessão de atendimento prioritário a idosos, ambos da Vara de Registros de São Paulo - SP. Na primeira foi negada por força da previsão legal específica a respeito na Lei 8.906/1994 - Estatuto da Ordem dos Advogados do Brasil, e da violação à ordem de precedência, todavia, foi feita recomendação para que se concedesse atendimento prioritários nos casos em que notários e registrados julgassem, sob prudentes critérios, necessário.

Já no segundo caso, os magistrados se valeram dos critérios definidos pela Lei 6.015/1973 e pelo Código Civil, afirmando que deveriam ser seguidos rigorosamente a ordem apresentada. Com isso, restou o entendimento de que seria concedido atendimento prioritário aos idosos no fornecimento de certidões ou na entrega de documentos, mas não no ingresso de títulos passíveis de gerar prioridade (LAGO, 2016).

A partir disso, é possível tomar esse entendimento também para o caso das pessoas com deficiência, já que seu Estatuto também prevê direito ao atendimento prioritário. Verificou-se que na visão das varas registrais, a disposição específica da Lei $n$. 6.015/1973 prevalece em relação ao direito de atendimento prioritário de determinados públicos, visto que trata de um direito material de prioridade, sendo entendido que conceder atendimento prioritário fora dos requisitos do art. 186 da Lei n. 6.015/1973, representaria inegável reconhecimento de causa extralegal, o que comprometeria o atendimento ao direito à igualdade, premissa também do Estatuto da Pessoa com Deficiência. 
O princípio da prioridade está previsto de forma expressa nos arts. 182 e seguintes, da Lei no 6.015/73. Cite-se, por exemplo, sua incidência sobre a hipoteca e atos que a cercam, embora redundante, consta também do Código Civil, no art. 1493, in verbis: "Os registros e averbações seguirão a ordem em que forem requeridas, verificando-se ela pela da sua numeração sucessiva no protocolo." Assim, não há como o pedido de uma pessoa portadora de deficiência teu seu pedido atendido antes daqueles que o sucederam em um Cartório. Nesse sentido Afrânio Carvalho (2011):

(...) num concurso de direitos reais sobre um imóvel, estes não ocupam todos o mesmo posto, mas se graduam ou classificam por uma relação de precedência fundada na ordem cronológica do seu aparecimento: prior tempore potior jure. Conforme o tempo em que surgirem, os direitos tomam posição no registro, prevalecendo os anteriormente estabelecidos sobre os que vierem depois. (CARVALHO, 2011, p. 216).

Elucida-se que os títulos que geram direito de prioridade devem ingressar no Registro Imobiliário, mediante lançamento no Livro no 1 - Protocolo, conforme a rigorosa ordem de apresentação descrita na Lei de Registros Públicos. Por essa razão, eventual direito a atendimento preferencial em razão de deficiência, idade, sexo não permitem, quanto a esses títulos, que sejam recebidos antes de outros que já deram ingresso nas dependências da serventia em primeiro lugar. Aplicando-se o princípio da prioridade registral deverá ser registrado título prenotado em primeiro lugar, de acordo com o número de protocolo mais baixo, "protelando-se o registro dos apresentados posteriormente, pelo prazo correspondente a, pelo menos, um dia útil" (Lei 6.015/73, art. 191). Todavia, apesar de não se aplicar o princípio da prioridade ao deficiente, em ambos os casos os títulos devem ser registrados.

Com vistas a solucionar o problema, Lago (2016, p. 316) sugere "um sistema de um sistema composto por um dispositivo fornecedor de senhas com certas características, e dois livros de protocolo simultâneos - um preliminar e um definitivo". Todavia, acredita-se que a problemática vai além, não sendo suficiente para solução, considerando a autonomia do sistema registral e o intuito de promulgação do Estatuto da Pessoa com Deficiência, entende-se que o atendimento prioritário nesse caso não deve ocorrer, sob pena de lesar o direito à igualdade. 


\section{CONCLUSÃO}

Os serviços notariais e registrais foram abordados neste estudo considerando-os em sua atividade realizada pela esfera privada por delegação do Poder Público, levando em conta ser voltado para o interesse social, portanto, devendo obediência aos princípios gerais da Administração Pública, além de princípios específicos a essas atividades que devem ser observados em cada ato.

Além da obediência a princípios específicos dessas atividades, que são 0 da inscrição, o da publicidade, o da presunção da verdade, o da prioridade, o da especialidade ou determinação dos registros, o da qualificação, da legalidade ou da legitimidade, o da continuidade e da instância ou rogação, bem como da fé pública, que um dos principais mencionados na jurisprudência.

O assunto foi tratado sob a ótica de que, embora os direitos às pessoas com deficiência estejam garantidos na Constituição Federal, a realidade revela muita distância entre os direitos formais e a efetividade dos mesmos, verificando-se que inúmeras foram as políticas públicas voltadas para as pessoas com deficiência no decorrer da história em busca de acessibilidade, mobilidade e igualdade dos direitos, integrando-os à sociedade, todavia, evidencia-se que ainda existe um significativo caminho a ser percorrido para que seus direitos de fato venham a ser efetivados.

No âmbito do sistema registral verificou-se que há um conflito entre suas disposições do princípio da prioridade registral e o Estatuto da Pessoa com Deficiência que prevê o atendimento prioritário a esse público. Acontece que nesse sistema se tem os direitos materiais como foco, portanto, considerar o Estatuto da Pessoa com Deficiência para atendimento prioritário traria consequências como a possibilidade de burlar ou fraudar o sistema legal vigente no país.

Dessa forma, a partir de decisões semelhantes tomadas pelas varas registrais de São Paulo percebeu-se que a disposição específica da Lei n. 6.015/1973 prevalece em relação ao direito de atendimento prioritário de determinados públicos, visto que trata de um direito material de prioridade, sendo entendido que conceder 
atendimento prioritário fora dos requisitos do art. 186 da Lei n. 6.015/1973, representaria inegável reconhecimento de afronta a direitos reais dos cidadãos, o que comprometeria o atendimento ao direito à igualdade, premissa também do Estatuto da Pessoa com Deficiência.

Por fim, como forma de responder à questão norteadora desse ensaio, tem-se que a garantia do mecanismo de prioridade registral não contrasta com a faculdade consagrada genericamente no Estatuto da Pessoa com Deficiência. As regras deste não se impõem às regras da Lei 6.015/1973. Tratam, tais diplomas, de situações distintas entre si. Em outras palavras, vale a regra protetiva até o limite em que não seja excluída por outra, de ordem pública, que consagra, aos interessados, a prioridade registral e na ponta remota a preferência e definição dos direitos reais.

\section{REFERÊNCIAS}

ANTUNES, Luciana Rodrigues. Introdução ao Direito Notarial e Registral. Jus Navigandi, Teresina, ano 9, n. 691, 2005.

BIANCHETTI, Lucídio; FREIRE, Ida Mara (orgs.). Um olhar sobre a diferença: interação, trabalho e cidadania. 6. ed. São Paulo: Papirus. 2007.

BRASIL. Constituição da República Federativa do Brasil, de 05 de outubro de 1988. Brasília, 1988. Diário Oficial da União. Disponível em: http://www.planalto.gov.br/ccivil_03/Constituicao/Constituicao.htm Acesso em: julho.2021.

BRASIL. Decreto no 5.296 de 2 de dezembro de 2004. Diário Oficial da União, 3 dez. 2004. Disponível em: http://www.planalto.gov.br/ccivil_03/_ato20042006/2004/decreto/d5296.htm . Acesso em: 25 jul. 2021.

BRASIL. Lei n. 13.105, de 16 de março de 2015. Disponível em: <https://www.planalto.gov.br/ccivil_03/_ato2015-2018/2015/lei/l13105.htm> Acesso em: jul.2021. 
BRASIL. Lei no 10.406, de 10 de janeiro de 2002. Institui o Código Civil. Diário Oficial da União: seção 1, Brasília, DF, ano 139, n. 8, p. 1-74, 11 jan. 2002.

BRASIL. Lei nº. 10.048, de 08 de Novembro de 2000. Diário Oficial [da República Federativa do Brasil], Brasília. Disponível em: https://www.presidencia.gov.br/ccivil_03/Leis/L10048.htm . Acesso em: 30jul.2021.

BRASIL. Lei nº. 10.098, de 19 de Dezembro de 2000. Diário Oficial [da República Federativa do Brasil], Brasília. Disponível em: https://www.presidencia.gov.br/ccivil_03/Leis/L10098.htm . Acesso em: 30jul.2021.

BRASIL. Presidência da República. Lei 7.853 de 24 de outubro de 1989. Disponível em:http://www.planalto.gov.br/ccivil_03/leis/l7853.htm - Acesso em 26/07/2021.

CARTA Mundial do Direito à Cidade. Fórum Social das Américas - Quito - Julho 2004; Fórum Mundial Urbano - Barcelona - Setembro 2004; V Fórum Social Mundial - Porto Alegre - Janeiro 2005. Disponível em: Acesso em: 30 jul. 2021.

CARVALHO, Afrânio de. Registro de imóveis. Rio de Janeiro: Editora Forense, 2011.

CENEVIVA, Walter. Lei dos notários e registradores comentada. São Paulo: Saraiva, 2008.

CLEMENTE, Carlos Aparício. Lei de cotas para o trabalho de pessoas com deficiência: Análise e fundamentação dos principais argumentos favoráveis e contrários ao seu cumprimento. 2015.

GALIANI, Luiz Antônio. Os princípios basilares do fólio real. RJ n. 212, jun/95.

GOFFMAN, Erving. Estigma: notas sobre a manipulação da identidade deteriorada. $4^{a}$. ed. Rio de Janeiro:LTC, 2008. 
GUGEL, Maria Aparecida. Benefício da prestação continuada e trabalho: Mudanças da Lei $N^{\circ} 12.470$, de 31 de agosto de 2011. Disponível em: Acesso em jul.2021.

KOYAMA, D. B. Os reflexos da lei 13.146/2015 - Estatuto da Pessoa com Deficiência - no sistema jurídico brasileiro. Universidade Presbiteriana Mackenzie, São Paulo, 2017.

LAGO, Ivan Jacopetti do. O atendimento prioritário da Lei Federal 13.146/2015 (Estatuto da Pessoa Com Deficiência) e o princípio da prioridade do registro de imóveis.Revista de Direito Imobiliário,São Paulo, ano 39, v.80, jan-jun.2016.

LORENTEZ, Lutiana Nacur. A norma da igualdade e o trabalho das pessoas portadoras de deficiência. São Paulo: LTr, 2006.

MAINIERI, Tiago; ROSA, Elisa Costa Ferreira. Comunicação pública, cidadania e democracia-algumas reflexões. Revista Comunicação Midiática, v. 7, n. 1, p. p. 192-206, 2012.

ORGANIZAÇÃO DAS NAÇÕES UNIDAS (ONU). Declaração de Direitos do Deficiente Mental - 1971. Aprovada pela resolução n. A/8429 da Assembleia Geral da ONU de 22 de dezembro de 1971. Disponível em: http://www.direitoshumanos.usp.br/index.php/Direito-dos-Portadores-deDefici\%C3\%AAncia/declaracao-de-direitos-do-deficiente-mental.html. Acesso em $27 / 07 / 2021$.

SILVA, C. H. R. Teoria das Incapacidades. [online]. 2008. Disponível em: <http://www.ribeirodasilva.pro.br/teoriadasincapacidades.html> Acesso em: jul.2021.

VASCONCELOS, Julenildo Nunes; CRUZ, Antônio Augusto Rodrigues. Direito notarial: teoria e prática. [S.I.] Juarez de Oliveira, 2000. 


\section{APÊNDICE - REFERÊNCIA NOTA DE RODAPÉ}

4. Conjunto de medidas jurídicas destinadas a proteger situações em vias de constituição, modificação ou extinção.

5. Conjunto de medidas jurídicas apropositadas a conservar situações estabelecidas

6. Estabelece normas gerais e critérios básicos para a promoção da acessibilidade das pessoas portadoras de deficiência ou com mobilidade reduzida, e dá outras providências.

7. Regulamenta as Leis nos 10.048 , de 8 de novembro de 2000 , que dá prioridade de atendimento às pessoas que especifica, e 10.098, de 19 de dezembro de 2000, que estabelece normas gerais e critérios básicos para a promoção da acessibilidade das pessoas portadoras de deficiência ou com mobilidade reduzida, e dá outras providências.

8. Dá prioridade de atendimento às pessoas que especifica, e dá outras providências.

Enviado: Julho, 2021.

Aprovado: Setembro, 2021.

RC: 96916

Disponível em: https://www.nucleodoconhecimento.com.br/lei/atendimento-prioritario 